\title{
Cardiovascular and metabolic risk markers are related to parasympathetic indices in pre-pubertal adolescents
}

\author{
Suziane U. Cayres, ${ }^{1,2}$ Luiz Carlos M. Vanderlei, ${ }^{3}$ Danilo R. P. Silva, ${ }^{4}$ Manoel Carlos S. Lima, ${ }^{1,2}$ \\ Maurício F. Barbosa, ${ }^{5}$ Rômulo A. Fernandes ${ }^{1,2}$ \\ ${ }^{1}$ Post-Graduate Program in Movement Sciences, Sao Paulo State University, Rio Claro; ${ }^{2}$ Laboratory of Investigation in \\ Exercise, Department of Physical Education; ${ }^{3}$ Department of Physical Therapy, Sao Paulo State University, Presidente \\ Prudente, Sao Paulo; ${ }^{4}$ Center of Physical Education and Sport, Londrina State University, Londrina, Brazil; ${ }^{5}$ Program of \\ Post-Graduate in Radiology, Federal University of Sao Paulo-UNIFESP, Sao Paulo, Brazil
}

\begin{abstract}
Objective: To analyse the relationship between different heart rate variability indices, resting heart rate, and cardiovascular markers in adolescents. Methods: A cross-sectional study was carried out with information from an ongoing cohort study. The sample was composed of 99 adolescents who complied with the following inclusion criteria: aged between 11 and 14 years; enrolled in a school unit of elementary education; absence of any known diseases; no drug consumption; and a formal consent signed by the parents or legal guardians. Weight, height, heart rate variability, lipid profile, inflammatory markers, blood pressure, resting heart rate, intima-media thickness, blood flow, and trunk fatness were measured. Partial correlation and linear regression (expressed by $\beta$ and $95 \%$ confidence intervals [95\% CI]) analyses were used to analyse the relationships between the variables. Results: In the linear regression analysis, even after adjustments for sex, age, trunk fatness, and somatic maturation, parasympathetic activity presented significant correlations with maximum carotid artery blood flow $(\beta=-0.111[95 \% \mathrm{CI}=-0.216 ;-0.007])$, systolic blood pressure $(\beta=-0.319[95 \% \mathrm{CI}=-0.638 ;-0.001])$, and resting heat rate $(\beta=-0.005[95 \% \mathrm{CI}=-0.009 ;-0.002])$. Conclusion: Parasympathetic activity at rest is inversely related to maximum and minimum blood flow, triacylglycerol levels, and systolic blood pressure. These findings suggest that heart rate variability has the potential to discriminate pre-pubertal adolescents at increased risk.
\end{abstract}

Keywords: Children; atherosclerosis; heart rate variability; cardiovascular risk

Received: 24 October 2014; Accepted: 13 January 2015; First published online: 24 February 2015

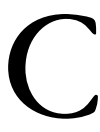
ARDIOVASCULAR DISEASES CONSTITUTE A PUBLIC health problem in both developed and developing nations around the world. ${ }^{1}$ Therefore, great effort has been made to identify non-invasive and inexpensive tools to screen individuals at increased risk for cardiovascular diseases. With this in mind, heart rate variability has been used in different studies in order to analyse autonomic modulation patterns, ${ }^{2}$ principally because it is a

Correspondence to: S. U. Cayres, MSc, Department of Physical Education, Roberto Simonsen Street 305, 19060900 Presidente Prudente, São Paulo, Brazil. Tel: + 183229 5400; Fax: (18) 3221 4391; E-mail: suziungari@yahoo.com.br simple and non-invasive marker for identifying disorders in autonomic patterns through oscillations between consecutive heartbeat intervals. ${ }^{2}$

In recent years, studies have linked heart rate variability in adults with increased risk of hospitalisation and early mortality; ${ }^{3,4}$ however, most of these studies involved adults with some previous cardiovascular complication - for example, acute myocardial infarction and acute coronary syndrome $-{ }^{3,4}$ and it is not clear whether these results can be applied to healthy populations.

In paediatric populations, although heart rate variability has been related to higher adiposity and 
blood pressure, ${ }^{5-7}$ its use in children and adolescents seems greatly affected by maturational variables. Despite this, however, most studies investigating the issue do not take maturational variables into account, using chronological age instead. ${ }^{8,9}$

Moreover, outcomes directly related to autonomic modulation, such as resting heart rate, have been indicated as promising cardiovascular risk factors in paediatric populations; ${ }^{8}$ however, it is not clear whether these different variables - resting heart rate and heart rate variability indices, such as high frequency and the root mean square of successive differences, both indicators of parasympathetic activity in the frequency and time domain, respectively - although biologically linked, are similarly related to cardiovascular outcomes. Thus, more scientific effort should be made to overcome the limitations observed in previous studies, instead of merely discussing these limitations without any significant advances in the issue. ${ }^{10}$

The aim of this study was to analyse the relationship of the parasympathetic index and resting heart rate with cardiovascular risk markers in adolescents.

\section{Materials and methods}

Sample

The present study constitutes the baseline measures of a cohort study, carried out in Presidente Prudente city (200,000 inhabitants; western São Paulo State, Brazil) from July to November, 2013. Initially, a minimum sample size was estimated $(r=0.26,80 \%$ of power and $\alpha$ of $5 \%),{ }^{11}$ which identified the need to recruit at least 86 adolescents. In the sampling process, seven large public and private schools in the metropolitan area of the city were invited to participate in the study, and of these three schools agreed to participate. In the participating schools, there were 495 school children with a chronological age between 11 and 14 years, who were invited to participate in the cohort. Among all, 120 adolescents agreed to participate and fulfilled all the following inclusion criteria: aged between 11 and 14 years; regularly enrolled in the school unit; absence of any known diseases; not consuming drugs; signature of parents or legal guardians. In the present study, 21 patients were excluded because they did not complete all the measurements, and thus the final sample size comprised 99 adolescents.

The study had been previously approved by the Human Research Ethics Committee (process: 322.650/2013) of the Universidade Estadual Paulista, Presidente Prudente, Brazil, and was in accordance with the National Health Council (Resolution no. 466/12).

\section{Heart rate variability}

Heart rate variability was analysed using a heart rate monitor (model RS800; Polar ${ }^{\circledR}$, Kempele, Finland). Each heartbeat was monitored for 30 minutes at rest in a laboratory at the university (supine position, spontaneous breathing, on a stretcher). Electrodes were positioned at the xiphoid process of the sternum. The receptor device (clock) was placed on the wrist and the arms were extended alongside the body. All the adolescents were instructed to avoid caffeine consumption and physical activity for 24 hours before testing. ${ }^{4}$ Evaluations were performed in the morning in order to avoid possible influences of circadian rhythm in an acclimatised room with an ambient temperature of $25^{\circ} \mathrm{C}\left( \pm 1^{\circ} \mathrm{C}\right)$.

Heart rate variability analysis was performed using the linear method in the time and frequency domains. ${ }^{2}$ In the time domain, the root mean square of successive differences was used, expressed in milliseconds. In the frequency domain, the spectral components of high frequency $(0.15-0.40 \mathrm{~Hz})$ were used, in normalised units. All data were downloaded using Polar Pro Trainer software, version 5.41.002. The method for filtering data was performed in two stages: automatic filter by the Polar Pro Trainer software, version 5.41.002 and manual filter to select extreme artefacts. ${ }^{2}$ A thousand heartbeat intervals ${ }^{2}$ were analysed and only series of $>95 \%$ sinus beats were evaluated. The heart rate variability indices were calculated using the software Kubios, version 2.0. ${ }^{12}$

\section{Biochemical variables}

Blood samples were collected in the morning, after 12 hours of fasting, by a nurse in a private laboratory, which met all the quality-control standards adopted by the Brazilian Health Ministry. High-density lipoprotein cholesterol; low-density lipoprotein cholesterol; and triacylglycerol levels were measured using an enzymatic colorimetric kit processed in an Autohumalyzer (Dimension RxL Max model Siemens; Dade-Behring Deerfield, Illinois, USA). The high-sensitivity C-reactive protein was determined through the turbidimetric method (LABEST brand model LabMax 240 Chema Diagnostica, Monsano, Italy) using an enzyme kit (Millipore, St. Charles, MO, United States of America) intra- and inter-assay coefficients ranging between 4.6 and 6.0 kit $\%$, respectively.

\section{Blood pressure and resting heart rate}

Systolic and diastolic blood pressure, as well as resting heart rate were assessed using the oscillometric method in an automatic device (Intellisense model HEM 742 INT; Omron Healthcare Inc., Bannockburn, Illinois, United States of America), validated by Christofaro 
et $\mathrm{al}^{13}$ and used in adolescents. ${ }^{8}$ All measurements were performed after 10 minutes at rest in the seated position. A cuff of appropriate size for the arm circumference - aged under 13 years [child size] $(6 \times 12 \mathrm{~cm})$ and aged 13 years or over [medium size] $(9 \times 18 \mathrm{~cm})$ - was wrapped around the midpoint of the humerus of the right arm. Adjustments were made where necessary for obese adolescents with an arm circumference greater than that of their age group. In all, three measurements were taken, separated by an interval of 1 minute, and the average of the final two measurements was considered as the blood pressure. ${ }^{14}$

\section{Intima-media thickness and blood flow}

The intima-media thickness and (maximum and minimum) blood flow of the carotid and femoral artery were assessed by a trained doctor using a Doppler ultrasound device (model Philips HD 11 XE; Philips, Brazil), equipped with a highresolution, multi-frequency linear transducer, set to $12 \mathrm{MHz}$, in a private hospital in the city. All recommendations of the Brazilian Society of Cardiology ${ }^{15}$ were adopted for this procedure. The common carotid artery and femoral artery (right side) were evaluated to estimate intima-media thickness; in other words, the distance between two echogenic lines that show the lumen/intima interface and media/adventitia of the arterial wall. ${ }^{16}$ When testing the common carotid artery, the neck was slightly hyper-extended and inclined at an angle of $45^{\circ}$. To assess the femoral artery, the adolescent's leg was stretched out on the bed and the measurement was taken near the inguinal line.

The images were interpreted in real time by the doctor and stored in a digital file; the medical doctor did not know the results of the other tests performed for this study. The study of the vessels started with a B-mode ultrasound picture, evaluating the structure of the arterial wall, for wall thickening and any plaque, followed by studies with a pulsed and colour Doppler (spectral mode).

Measurements of the blood flow in centimetres per second were carried out, obtaining maximum values of systolic peaks (maximum blood flow) and minimum diastolic pressure (minimum blood flow) in the common carotid and common femoral arteries, both in the right side, using an automatic method with minimal adjustments when necessary. ${ }^{15}$ Reproducibility of ultrasound measurements were performed in a sub-sample ( $\mathrm{n}=16$ adolescents) and scores ranged from ICC $=0.57$ to ICC $=0.91$.

Trunk fatness

Trunk fatness - that is, percentage of fat in the trunk region - was assessed using a dual-energy $\mathrm{X}$-ray absorptiometry scanner (Lunar DPX-NT; General Electric Healthcare, Little Chalfont, Buckinghamshire, United Kingdom) with GE Medical System Lunar software, version 4.7; this variable being expressed as a percentage. The scanner quality was tested by a trained researcher before each measurement, in accordance with the manufacturer's recommendations. Following this stage, an examination of the entire body was performed. Throughout the test, the patients wore light clothing, without shoes, and remained in the supine position on the machine, remaining immobile for $\sim 15$ minutes.

\section{Biological maturation and other information}

In the face-to-face interview, ethnicity - white, black, oriental, and other - sex, and chronological age were established. In addition, body weight was measured using an electronic scale (Filizzola PL 150 model; Filizzola Ltda, Sao Paulo, Brazil), and height was measured using a wall-mounted stadiometer (Sanny model; American Medical of the Brazil Ltda, Sao Paulo, Brazil). The cephalic trunk height and leg length - stature minus cephalic trunk height - were also measured. These measurements were used to calculate the somatic maturation using sex-specific equations proposed by Mirwald et al. ${ }^{17}$ The result of these equations denotes the time (in years) before (negative values) or after (positive values) the estimated peak height velocity (maturity offset). All anthropometric measurements were performed according to standardised techniques.

\section{Statistical analyses}

Descriptive statistics were composed of minimum and maximum values, means and a $95 \%$ confidence interval $(95 \% \mathrm{CI})$, median, and interquartile range. The bivariate Pearson correlation and its $95 \% \mathrm{CI}$ were used to analyse the relationship among the variables. Second, partial correlations and linear regression (expressed by $\beta$ and $95 \% \mathrm{CI}$ ) were performed, controlled by sex, age, trunk fatness, and somatic maturation. Statistical significance was set at $5 \%$ (p-value $<0.05$ ), and all statistical analyses were performed using the software BioEstat (version 5.0, Tefé, Amazonas, Brazil).

\section{Results}

In the present study, the overall sample was composed of 99 adolescents of both sexes ( 49 boys), aged between 11 and 13 years (mean age $11.6 \pm 0.7$ years). In general, the adolescents were $>2$ years before their peak height velocity (maturity offset: mean: -2.2 [95\% CI: $-2.5 ;-2.2]$ ). All descriptive data are shown in Table 1. 
Table 1. Descriptive statistics of the study variables (Presidente Prudente, São Paulo, Brazil, 2013).

\begin{tabular}{|c|c|c|c|}
\hline \multirow[b]{2}{*}{ Variables } & \multicolumn{2}{|c|}{ Descriptive statistics } & \multirow[b]{2}{*}{ Median (IR) } \\
\hline & (Min; Max) & Mean $(95 \% \mathrm{CI})$ & \\
\hline \multicolumn{4}{|l|}{ Cardiovascular } \\
\hline CIMT (mm) & $(0.40 ; 0.71)$ & $0.46(0.44 ; 0.47)$ & $0.45(0.05)$ \\
\hline FIMT (mm) & $(0.28 ; 0.83)$ & $0.39(0.37 ; 0.41)$ & $0.39(0.09)$ \\
\hline Min Bflow ${ }_{\text {carotid }}(\mathrm{cm} /$ second $)$ & $(18.8 ; 83.6)$ & $36.4(34.4 ; 38.4)$ & $36.5(8.5)$ \\
\hline Max Bflow carotid $(\mathrm{cm} /$ second $)$ & $(66 ; 200)$ & $138.4(132.2 ; 144.7)$ & $140.0(35)$ \\
\hline Min Bflow femoral $(\mathrm{cm} /$ second $)$ & $(1.0 ; 116.0)$ & $9.7(6.3 ; 13.0)$ & $1.9(13.8)$ \\
\hline Max Bflow femoral $(\mathrm{cm} /$ second $)$ & $(96 ; 265)$ & $152.3(145.6 ; 158.9)$ & $151.0(40)$ \\
\hline $\mathrm{SBP}(\mathrm{mmHg})$ & $(95.0 ; 151.0)$ & $112.7(110.4 ; 115.1)$ & $113.3(15.3)$ \\
\hline $\mathrm{DBP}(\mathrm{mmHg})$ & $(43.3 ; 113.0)$ & $69.9(67.5 ; 72.2)$ & $68.3(13.0)$ \\
\hline RHR (beats/minute) & $(53.3 ; 82.0)$ & $78.8(76.0 ; 81.6)$ & $77.0(13.7)$ \\
\hline \multicolumn{4}{|l|}{ Metabolic } \\
\hline HDL-c (mg/dl) & $(30 ; 81)$ & $49.4(46.7 ; 52.1)$ & $48.2(16)$ \\
\hline LDL-c (mg/dl) & $(51 ; 143)$ & $94.5(89.7 ; 99.3)$ & $95.3(30)$ \\
\hline TG $(\mathrm{mg} / \mathrm{dl})$ & $(33 ; 247)$ & $85.2(75.9 ; 94.6)$ & $76.6(49)$ \\
\hline \multicolumn{4}{|l|}{ Inflammatory marker } \\
\hline hsCRP (mg/L) & $(0 ; 12)$ & $1.57(1.10 ; 2.04)$ & $0.53(2)$ \\
\hline \multicolumn{4}{|l|}{ Adjustment } \\
\hline Age (years) & $(11 ; 13)$ & $11.6(11.4 ; 11.8)$ & $12.0(1)$ \\
\hline Maturity offset (years) & $(-6.0 ;-0.9)$ & $-2.2(-2.5 ;-2.2)$ & $-2.3(0.9)$ \\
\hline $\mathrm{TF}(\%)$ & $(10.0 ; 52.0)$ & $32.7(30.1 ; 35.2)$ & $33.5(18.9)$ \\
\hline \multicolumn{4}{|l|}{ HRV } \\
\hline rMSSD (ms) & $(9.9 ; 108.0)$ & $42.8(38.5 ; 47.0)$ & $45.7(25.9)$ \\
\hline $\mathrm{HF}(\nu)$ & $(6.3 ; 76.2)$ & $46.0(42.6 ; 49.3)$ & $46.2(20.5)$ \\
\hline
\end{tabular}

CIMT = carotid intima-media thickness; DPB = diastolic blood pressure; FIMT = femoral intima-media thickness; HDL-c = high-density lipoprotein cholesterol; $\mathrm{HF}=$ high frequency; $\mathrm{HRV}=$ heart rate variability; hsCRP = high-sensitivity C-reactive protein; $\mathrm{IR}=$ interquartile range; LDL-c $=$ low-

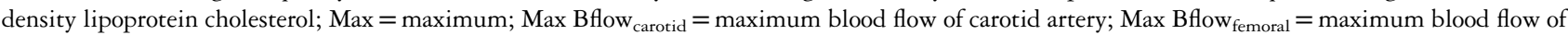
femoral artery; Min = minimum; Min Bflow ${ }_{\text {carotid }}=$ minimum blood flow of carotid artery; $\min$ Bflow $_{\text {femoral }}=$ minimum blood flow of femoral artery; $\mathrm{RHR}=$ resting heart rate; $\mathrm{rMSSD}=$ root mean square of successive differences; $\mathrm{SBP}=$ systolic blood pressure; $\mathrm{TF}=$ trunk fatness; $\mathrm{TG}=$ triacylglycerol; $95 \% \mathrm{CI}=$ confidence interval of $95 \%$

There were negative correlations between the root mean square of successive differences index and systolic blood pressure $(r=-0.271 \quad[95 \% \mathrm{CI}=-0.445$; $-0.078]$ ); the root mean square of successive differences index and triacylglycerol $(\mathrm{r}=-0.268[95 \% \mathrm{CI}=0.075$; $0.442]$ ); and the root mean square of successive differences index and trunk fat $(\mathrm{r}=-0.262[95 \% \mathrm{CI}=$ $-0.437 ;-0.068]$ ). Furthermore, there were positive relationships between resting heart rate and systolic blood pressure $(r=0.352[95 \% \mathrm{CI}=0.166 ; 0.514])$, diastolic blood pressure $(\mathrm{r}=0.431 \quad[95 \% \mathrm{CI}=0.255$; $0.579])$, and trunk fat $(r=0.331 \quad[95 \% \mathrm{CI}=0.143$; $0.496])$. There was statistical significance between high frequency and maximum blood flow of the carotid artery $(\mathrm{r}=-0.204 \quad[95 \% \mathrm{CI}=-0.386$; $-0.007]$ ); and between high frequency and systolic blood pressure $(\mathrm{r}=-0.235 \quad$ [95\% CI $=-0.413$; $-0.039]$ ) (Table 2).

For the partial correlations controlled by sex, age, trunk fatness, and biological maturation, there was statistical significance between the root mean square of successive differences index and triacylglycerol $(r=-0.224[95 \% \mathrm{CI}=-0.404 ;-0.028])$; high frequency and minimum blood flow of the carotid artery $(\mathrm{r}=-0.255[95 \% \mathrm{CI}=-0.431 ;-0.061]) ;$ high frequency and maximum blood flow of the carotid artery $(\mathrm{r}=-0.249 \quad[95 \% \mathrm{CI}=-0.425 ;-0.054])$; and high frequency and high-density lipoprotein cholesterol $(r=-0.209$ [95\%CI $=-0.390 ;-0.012])$. There were positive correlations between resting heart rate and systolic blood pressure $(\mathrm{r}=0.398[95 \%$ $\mathrm{CI}=0.218 ; 0.552]$ ) and diastolic blood pressure $(r=0.430[95 \% \mathrm{CI}=0.254 ; 0.578)$ (Table 3$)$. In the linear regression analysis, the parasympathetic indices were significantly related to resting heart rate, maximum blood flow of the carotid artery, and systolic blood pressure. Resting heart rate and diastolic blood pressure were still significantly related in the multivariate model (Table 4).

\section{Discussion}

Our results show that parasympathetic activity at rest in the domains analysed - time and frequency - is related to lower blood pressure, triacylglycerol, trunk fatness, and blood flow in pre-pubertal adolescents. In parallel, resting heart rate presented a positive relationship with blood pressure and trunk fatness. 
Table 2. Relationship between autonomic modulation and cardiovascular risk markers of health in adolescents (Presidente Prudente, São Paulo, Brazil, 2013).

\begin{tabular}{|c|c|c|c|}
\hline & $\operatorname{rMSSD}[r(95 \% \mathrm{CI})](\mathrm{ms})$ & $\mathrm{HF}[r(95 \% \mathrm{CI})](\nu)$ & RHR $[r(95 \% \mathrm{CI})]$ (beats/minute) \\
\hline \multicolumn{4}{|l|}{ Cardiovascular markers } \\
\hline CIMT $(\mathrm{mm})$ & $0.040(-0.159 ; 0.236)$ & $-0.067(-0.261 ; 0.132)$ & $-0.006(-0.203 ; 0.192)$ \\
\hline FIMT (mm) & $-0.138(-0.327 ; 0.061)$ & $-0.137(-0.326 ; 0.062)$ & $0.090(-0.109 ; 0.282)$ \\
\hline Min Bflow $_{\text {carotid }}(\mathrm{cm} /$ second $)$ & $-0.027(-0.233 ; 0.171)$ & $-0.185(-0.369 ; 0.013)$ & $0.052(-0.147 ; 0.247)$ \\
\hline Max Bflow carotid $(\mathrm{cm} /$ second $)$ & $-0.006(-0.203 ; 0.192)$ & $-0.204(-0.386 ;-0.007)$ & $-0.057(-0.252 ; 0.142)$ \\
\hline Min Bflow ${ }_{\text {femoral }}(\mathrm{cm} /$ second $)$ & $-0.102(-0.292 ; 0.097)$ & $0.004(-0.194 ; 0.201)$ & $0.102(-0.097 ; 0.294)$ \\
\hline Max Bflow femoral $(\mathrm{cm} /$ second $)$ & $-0.069(-0.263 ; 0.130)$ & $0.028(-0.170 ; 0.224)$ & $0.092(-0.107 ; 0.284)$ \\
\hline $\mathrm{SBP}(\mathrm{mmHg})$ & $-0.271(-0.445 ;-0.078)$ & $-0.235(-0.413 ;-0.039)$ & $0.352(0.166 ; 0.514)$ \\
\hline $\mathrm{DPB}(\mathrm{mmHg})$ & $-0.171(-0.356 ; 0.027)$ & $-0.010(-0.207 ; 0.188)$ & $0.431(0.255 ; 0.579)$ \\
\hline RHR (beats/minute) & $-0.374(-0.532 ;-0.191)$ & $0.009(-0.189 ; 0.206)$ & - \\
\hline \multicolumn{4}{|l|}{ Metabolic } \\
\hline HDL-c (mg/dl) & $0.052(-0.147 ; 0.247)$ & $-0.114(-0.305 ; 0.085)$ & $-0.176(-0.361 ; 0.022)$ \\
\hline LDL-c (mg/dl) & $-0.014(-0.211 ; 0.184)$ & $-0.154(-0.341 ; 0.045)$ & $0.057(-0.142 ; 0.252)$ \\
\hline $\mathrm{TG}(\mathrm{mg} / \mathrm{dl})$ & $-0.268(0.075 ; 0.442)$ & $-0.069(-0.263 ; 0.130)$ & $-0.051(-0.246 ; 0.148)$ \\
\hline \multicolumn{4}{|l|}{ Inflammatory marker } \\
\hline hsCRP (mg/L) & $-0,018(-0,215 ; 0,180)$ & $0.111(-0,088 ; 0,302)$ & $0.140(-0.059 ; 0.328)$ \\
\hline \multicolumn{4}{|l|}{ Adjustment } \\
\hline Age (years) & $0.065(-0.134 ; 0.259)$ & $0.078(-0.121 ; 0.271)$ & $-0.147(-0.335 ; 0.052)$ \\
\hline Maturiy offset (years) & $0.140(-0.059 ; 0.328)$ & $0.166(-0.032 ; 0.352)$ & $-0.180(-0.364 ; 0.018)$ \\
\hline $\mathrm{TF}(\%)$ & $-0.262(-0.437 ;-0.068)$ & $-0.115(-0.305 ; 0.084)$ & $0.331(0.143 ; 0.496)$ \\
\hline
\end{tabular}

CIMT = carotid intima-media thickness; DPB = diastolic blood pressure; FIMT = femoral intima-media thickness; HDL-c = high-density lipoprotein cholesterol; $\mathrm{HF}=$ high frequency; HRV = heart rate variability; hsCRP = high-sensitivity C-reactive protein; LDL-c = low-density lipoprotein choles-

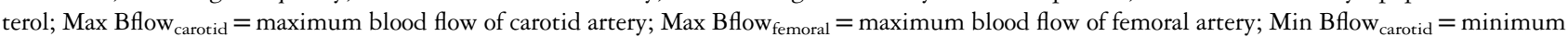
blood flow of carotid artery; Min Bflow femoral $=$ minimum blood flow of femoral artery; $r=$ correlation coefficient of Pearson; RHR $=$ resting heart rate $\mathrm{rMSSD}=$ root mean square of successive differences; $\mathrm{SBP}=$ systolic blood pressure; $\mathrm{TF}=$ trunk fatness; $\mathrm{TG}=$ triacylglycerol; $95 \% \mathrm{CI}=$ confidence interval of $95 \%$

Table 3. Relationship adjusted for sex, age, TF, and maturity offset between autonomic modulation and cardiovascular risk markers of health in adolescents (Presidente Prudente, São Paulo, Brazil, 2013).

\begin{tabular}{|c|c|c|c|}
\hline & rMSSD $[r(95 \% \mathrm{CI})](\mathrm{ms})$ & $\mathrm{HF}[r(95 \% \mathrm{CI})](\nu)$ & RHR $[r(95 \% \mathrm{CI})]$ (beats/minute) \\
\hline \multicolumn{4}{|l|}{ Cardiovascular markers } \\
\hline CIMT $(\mathrm{mm})$ & $0.046(-0.153 ; 0.241)$ & $-0.079(-0.272 ; 0.120)$ & $0.082(-0.117 ; 0.275)$ \\
\hline FIMT $(\mathrm{mm})$ & $-0.085(-0.278 ; 0.114)$ & $-0.136(-0.325 ; 0.063)$ & $0.060(-0.139 ; 0.254)$ \\
\hline Min Bflow $_{\text {carotid }}(\mathrm{cm} /$ second $)$ & $0.023(-0.175 ; 0.219)$ & $-0.255(-0.431 ;-0.061)$ & $-0.127(-0316 ; 0.072)$ \\
\hline Max Bflow carotid $(\mathrm{cm} /$ second $)$ & $-0.028(-0.224 ; 0.170)$ & $-0.249(-0.425 ;-0.054)$ & $-0.124(-0.314 ; 0.075)$ \\
\hline Min Bflow femoral $(\mathrm{cm} / \mathrm{second})$ & $-0.077(-0.270 ; 0.122)$ & $0.006(-0.192 ; 0.203)$ & $0.143(-0.056 ; 0.331)$ \\
\hline Max Bflow femoral $(\mathrm{cm} / \mathrm{second})$ & $0.073(-0.129 ; 0.267)$ & $0.091(-0.108 ; 0.283)$ & $-0.009(-0.206 ; 0.189)$ \\
\hline $\mathrm{SBP}(\mathrm{mmHg})$ & $-0.128(-0.317 ; 0.071)$ & $-0.081(-0.274 ; 0.118)$ & $0.398(0.218 ; 0.552)$ \\
\hline DBP $(\mathrm{mmHg})$ & $-0.009(-0.206 ; 0.189)$ & $0.116(-0.083 ; 0.306)$ & $0.430(0.254 ; 0.578)$ \\
\hline RHR (beats/minute) & $-0.291(-0.462 ;-0.099)$ & $0.077(0.122 ; 0.270)$ & - \\
\hline \multicolumn{4}{|l|}{ Metabolic } \\
\hline HDL-c (mg/dl) & $-0.031(-0.227 ; 0.167)$ & $-0.209(-0.390 ;-0.012)$ & $-0.188(-0.372 ; 0.010)$ \\
\hline LDL-c (mg/dl) & $0.061(-0.138 ; 0.255)$ & $-0.134(-0.323 ; 0.065)$ & $-0.076(-0.269 ; 0.123)$ \\
\hline $\mathrm{TG}(\mathrm{mg} / \mathrm{dl})$ & $-0.224(-0.404 ;-0.028)$ & $-0.034(-0.230 ; 0.165)$ & $-0.162(-0.348 ; 0.037)$ \\
\hline \multicolumn{4}{|l|}{ Inflammatory } \\
\hline hsCRP (mg/L) & $0.096(-0.103 ; 0.288)$ & $0.186(-0.012 ; 0.370)$ & $-0.009(-0.206 ; 0.189)$ \\
\hline
\end{tabular}

$\mathrm{CIMT}=$ carotid intima-media thickness; DPB $=$ diastolic blood pressure; FIMT $=$ femoral intima-media thickness; HDL-c $=$ high-density lipoprotein cholesterol; $\mathrm{HF}=$ high frequency; HRV = heart rate variability; hsCRP = high-sensitivity C-reactive protein; LDL-c = low-density lipoprotein cholesterol; Max

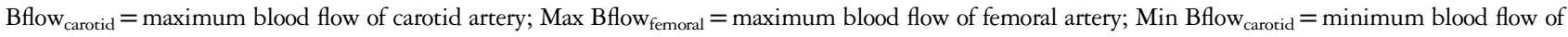
carotid artery; Min Bflow $_{\text {femoral }}=$ minimum blood flow of femoral artery; $r=$ correlation coefficient of Pearson; RHR $=$ resting heart rate; rMSSD $=$ root mean square of successive differences; $\mathrm{SBP}=$ systolic blood pressure; $\mathrm{TF}=$ trunk fatness; $\mathrm{TG}=$ triacylglycerol; $95 \% \mathrm{CI}=$ confidence interval of $95 \%$

These outcomes could indicate that both heart rate variability and resting heart rate are notably linked to cardiovascular risk in paediatric populations.
In this study, trunk fatness was negatively related to the root mean square of successive differences index. The literature shows that increased adipose tissue has 
Table 4. Adjusted linear regression between autonomic modulation and cardiovascular risk markers of health in adolescents (Presidente Prudente, São Paulo, Brazil, 2013).

\begin{tabular}{|c|c|c|c|}
\hline & $\operatorname{rMSSD}[\beta(95 \% \mathrm{CI})](\mathrm{ms})^{*}$ & $\operatorname{HF}[\beta(95 \% \mathrm{CI})](\nu)^{*}$ & RHR $[\beta(95 \% \mathrm{CI})]$ (beats/minute) $)^{*}$ \\
\hline \multicolumn{4}{|l|}{ Cardiovascular markers } \\
\hline Max Bflow ${ }_{\text {carotid }}(\mathrm{cm} /$ second $)$ & - & $-0.111(-0.216 ;-0.007)$ & - \\
\hline $\mathrm{SBP}(\mathrm{mmHg})$ & $-0.004(-0.009 ; 0.002)$ & $-0.319(-0.638 ;-0.001)$ & $0.200(-0.052 ; 0.453)$ \\
\hline $\mathrm{DPB}(\mathrm{mmHg})$ & & & $0.475(0.238 ; 0.711)$ \\
\hline RHR (beats/minute) & $-0.005(-0.009 ;-0.002)$ & - & - \\
\hline \multicolumn{4}{|l|}{ Metabolic } \\
\hline $\mathrm{TG}(\mathrm{mg} / \mathrm{dl})$ & $-0.001(-0.003 ; 0.001)$ & - & - \\
\hline
\end{tabular}

$\mathrm{DPB}=$ diastolic blood pressure; $\mathrm{HF}=$ high frequency; $\mathrm{Max} \mathrm{Bflow}_{\text {carotid }}=$ maximum blood flow of carotid artery; RHR = resting heart rate; rMSSD = root mean square of successive differences; $\mathrm{SBP}=$ systolic blood pressure; $\mathrm{TG}=$ triacylglycerol; $\beta=$ linear regression; $95 \% \mathrm{CI}=$ confidence interval of $95 \%$ *Adjusted by sex, age, trunk fatness, and maturity offset

been related to worse autonomic modulation. ${ }^{5}$ This pathway can be explained, at least partially, by the function of the sympathetic nervous system on the adrenal gland, stimulating the secretion of catecholamines - adrenaline and noradrenaline - which are responsible for lipolysis in adipose tissue via adrenoceptors $\beta 1$ and $\beta 2{ }^{18}$ In the same form, this pathway can be directly associated with triacylglycerol serum, as well as sympathetic hyperactivity stimulating the absorption of low-density lipoprotein cholesterol in endothelial cells, contributing to atherosclerotic formation. ${ }^{18}$ It is noteworthy that our sample was composed only of pre-pubertal adolescents who had not experienced the growth spurt, which dramatically increases the quantity of adipose tissue in a relatively short period of time (mainly in obese patients) ${ }^{19}$ and which would boost the harmful effects of adiposity during later adolescence.

In parallel, the root mean square of successive differences index was inversely related to systolic blood pressure in both the domains analysed - that is, time and frequency. Our results are in concordance with previous literature, which shows that vagal response can be reduced by excess body fat and high blood pressure. ${ }^{7}$ Besides this, such autonomic behaviour could be related to blood flow in response to cardiac output and resting heart rate. In our study it was found that regardless of adjustments - that is, for sex, age, trunk fat, and maturity offset - the maximum blood flow of the carotid artery was related to parasympathetic activity, and this fact may be explained by the influence of resting heart rate on blood pressure, indirectly associated with blood flow velocity. Besides this, resting heart rate demonstrated a positive relationship with trunk fatness and blood pressure, regardless of adjustments for sex, age, trunk fat, and maturity offset. This fact seems to be affected by the interaction between body fat and blood flow, which is related to blood pressure.

On the other hand, carotid intima-media thickness, femoral intima-media thickness, and high-sensitivity
C-reactive protein were not significantly related to autonomic modulation. Regarding intima-media thickness, the vessel's architecture is modified throughout life and ageing acts on this morphological process, which can be exacerbated if behavioural risk factors are incorporated into lifestyle, such as smoking and physical inactivity. ${ }^{20,21}$ Similar effects on intima-media thickness have been observed from early life when the effects of cardiorespiratory fitness $^{21}$ and physical exercise ${ }^{22,23}$ are considered. A possible explanation for the absence of significant relationships could be based on the fact that these types of morphological outcomes have been observed in older adolescents, after the effects of the growth spurt on adipose tissue, ${ }^{24}$ and young adults exposed over the years to behavioural risk factors. ${ }^{20,21}$ Moreover, in our study, the sample was not composed of obese adolescents, affecting high-sensitivity $\mathrm{C}$-reactive protein concentrations, and half of the adolescents reported participating in organised sports practice outside school (data not shown).

In addition, high-density lipoprotein cholesterol presented negative correlations with the root mean square of successive differences index and high frequency, but this response was regardless of the adjustment only in the frequency domain. The direct relationship between high-density lipoprotein cholesterol and the parasympathetic indices demonstrates the protective importance of this lipoprotein in tackling illnesses associated with vasculature, for instance, atherosclerosis. ${ }^{25} \mathrm{~A}$ significant review showed that the atherogenic process can begin in the first decade of life ${ }^{26}$ and that high-density lipoprotein cholesterol has an essential function, principally to stimulate the enzyme expression of the endothelial nitric oxide synthase, and that physical exercise is associated with reverse cholesterol transport. ${ }^{27}$ Taken together, these facts could be related to vasodilatation of the smooth muscle of the blood vessel mediated by oxide nitric. ${ }^{25,28}$ Furthermore, higher high-density lipoprotein cholesterol can also be related to a 
predominance of parasympathetic activity and lower lipolysis rate, and thus can promote amelioration in the lipid profile. This autonomic behaviour, however, still requires further research.

The adjustment by biological maturation is a strong point of this study. The role of maturational processes is noteworthy in the analysed outcomes. ${ }^{29}$ For example, prematurity is associated with some alterations in myocardial tissue Doppler velocity in preterm, and therefore it has the potential to influence the heart rate variability index in childhood. ${ }^{29}$ On the other hand, the burden of the interaction between prematurity and genetics/behavioural factors on heart rate variability is still unclear, and future studies are necessary to assess this issue.

Some limitations need to be clarified: the crosssectional design of the baseline measures should be taken into account, because it does not offer support to causal relationships among outcomes; the adolescents breathed spontaneously, and thus there was no control of breathing rate, and this fact may have promoted alterations in the high frequency index; moreover, the absence of reproducibility measurements related to heart rate variability should be taken into account, as in this study parents were reluctant to bring adolescents to the laboratory twice to perform the same measurement. Finally, measurements of insulin resistance might be useful to understand the biological pathways behind our results and should be considered for future studies.

In conclusion, our data suggest that, independent of maturation and trunk fatness, parasympathetic activity and resting heart rate are related to different cardiovascular outcomes. Apparently, both variables could be used to screen different cardiovascular outcomes in paediatric populations.

\section{Acknowledgement}

None.

\section{Financial Support}

The authors thank the State of São Paulo Research Support Foundation (FAPESP [Process: 2013/ 06052-2]) and CNPq (Process: 476295/2013-0) for funding this research project.

\section{Conflicts of Interest}

None.

\section{Ethical Standards}

The study had been previously approved by the Human Research Ethics Committee (process: $322.650 / 2013$ ) and was in accordance with National Health Council (Resolution no. 466/12).

\section{References}

1. Juonala M, Magnussen CG, Berenson GS, et al. Childhood adiposity, adult adiposity, and cardiovascular risk factors. $\mathrm{N}$ Engl J Med 2011; 365: 1876-1885

2. Vanderlei LC, Pastre CM, Hoshi RA, Carvalho TD, Godoy MF. Basic notions of heart rate variability and its clinical applicability. Rev Bras Cir Cardiovasc 2009; 24: 205-217.

3. Harris PR, Stein PK, Fung GL, Drew BJ. Heart rate variability measured early in patients with evolving acute coronary syndrome and 1-year outcomes of rehospitalization and mortality. Vasc Health Risk Manag 2014; 10: 451-464.

4. Song T, XF Qu, Zhang YT, et al. Usefulness of the heart-rate variability complex for predicting cardiac mortality after acute myocardial infarction. BMC Cardiovasc Disord 2014; 14: 59.

5. Altuncu ME, Baspinar O, Keskin M. The use of short-term analysis of heart rate variability to assess autonomic function in obese children and its relationship with metabolic syndrome. Cardiol J 2012; 19: 501-506

6. Pal GK, Adithan C, Ananthanarayanan PH, et al. Association of sympathovagal imbalance with cardiovascular risks in young prehypertensives. Am J Cardiol 2013; 112: 1757-1762.

7. Zhou Y, Xie G, Wang J, Yang S. Cardiovascular risk factors significantly correlate with autonomic nervous system activity in children. Can J Cardiol 2012; 28: 477-482.

8. Fernandes RA, Ronque ERV, Venturini D, et al. Resting heart rate: its correlations and potential for screening metabolic dysfunctions in adolescents. BMC Pediatrics 2013; 13: 48.

9. Rabbia F, Grosso T, Genova GC, et al. Assessing resting heart rate in adolescents: determinants and correlates. J Hum Hypertens 2002; 16: 327-332.

10. de Moraes AC, Cassenote AJ, Moreno LA, Carvalho HB. Potential biases in the classification, analysis and interpretations in crosssectional study: commentaries - surrounding the article "resting heart rate: its correlations and potential for screening metabolic dysfunctions in adolescents". BMC Pediatr 2014; 14: 117.

11. Miot HA. Sample size in clinical and experimental trials. J Vasc Bras 2011; 10: 275-278.

12. Tarvainen MP, Niskanen JP, Lipponen JA, Rantaaho PO, Karjalainen PA. Kubios HRV - a software for advanced heart rate variability analysis. ECIFMBE 2008: 1022-1025.

13. Christofaro DG, Fernandes RA, Gerage AM, Alves MJ, Polito MD, Oliveira AR. Validation of the Omron HEM 742 blood pressure monitoring device in adolescents. Arq Bras Cardiol 2009; 92: $10-15$.

14. Pickering TG, Hall JE, Appel LJ, Falkner BE, Graves J. Subcommittee of Professional and Public Education of the American Heart Association Council on High Blood Pressure Research. Recommendations for blood pressure measurement in humans and experimental animals: part 1: blood pressure measurement in humans: a statement for professionals from the Subcommittee of Professional and Public Education of the American Heart Association Council on High Blood Pressure Research. J Hypertens 2005; 5: 142-161.

15. Brazilian Society of Cardiology. Standardization of equipment and techniques for conducting examinations vascular ultrasonography. Arq Bras Cardiol 2004; 82: 1-15.

16. Jourdan C, Wühl E, Litwin M, Fahr K, Trelewicz J, Jobs K. Normative values for intima-media thickness and distensibility of large arteries in healthy adolescents. J Hypertens 2005; 2: $1707-1715$.

17. Mirwald RL, Baxter-Jones AD, Bailey DA, Beunen GP. An assessment of maturity from anthropometric measurements. Med Sci Sports Exerc 2002; 34: 689-694.

18. Zouhal H, Lemoine-Morel S, Mathieu ME, Casazza GA, Jabbour G. Catecholamines and obesity: effects of exercise and training. Sports Med 2013; 43: 591-600. 
19. Knittle JL, Timmers K, Ginsberg-Fellner F, Brown RE, Katz DP. The growth of adipose tissue in children and adolescents. Crosssectional and longitudinal studies of adipose cell number and size. J Clin Invest 1979; 63: 239-246.

20. Katano H, Ohno M, Yamada K. Protection by physical activity against deleterious effect of smoking on carotid intima-media thickness in young Japanese. J Stroke Cerebrovasc Dis 2013; 22: 176-183.

21. Li S, Yun M, Fernandez C, et al. Cigarette smoking exacerbates the adverse effects of age and metabolic syndrome on subclinical atherosclerosis: the Bogalusa Heart Study. PLoS One 2014; 9: e96368.

22. Pahkala K, Laitinen TT, Heinonen OJ, et al. Association of fitness with vascular intima-media thickness and elasticity in adolescence. Pediatrics 2013; 132: 77.

23. Pahkala K, Heinonen OJ, Simell O, et al. Association of physical activity with vascular endothelial function and intima-media thickness. Circulation 2011; 124: 1956-1963.
24. Christofaro DG, Fernandes RA, Oliveira AR, Freitas Júnior IF, Barros MV, Ritti-Dias RM. The association between cardiovascular risk factors and high blood pressure in adolescents: a schoolbased study. Am J Hum Biol 2014; 26: 518-522.

25. Yuhanna IS, Zhu Y, Cox BR, et al. High-density lipoprotein binding to scavenger receptor-BI activates endothelial nitric oxide synthase. Nat Med 2001; 7: 853-857.

26. Herouvi D, Karanasios E, Karayianni C, Karavanaki K. Cardiovascular disease in childhood: the role of obesity. Eur J Pediatr 2013; 172: 721-732.

27. Leaf DA. The effect of physical exercise on reverse cholesterol transport. Metabolism 2003; 52: 950-957.

28. Zago AS, Zanesco A. Nitric oxide, cardiovascular disease and physical exercise. Arq Bras Cardiol 2006; 87: e264-e270.

29. Ciccone MM, Scicchitano P, Zito A, et al. Different functional cardiac characteristics observed in term/preterm neonates by echocardiography and tissue Doppler imaging. Early Hum Dev 2011; 87: 555-558 